\title{
Reading and screen flicker
}

SIR - We were motivated by the Scientific Correspondence ${ }^{1}$ by Kennedy and Murray, who suggested an adverse effect of higher CRT-display refresh rates on saccadic extent and performance during reading, to investigate the problem further. Kennedy and Murray's experiment deviated extensively from normal reading, as only three separate words were involved in a two-alternative

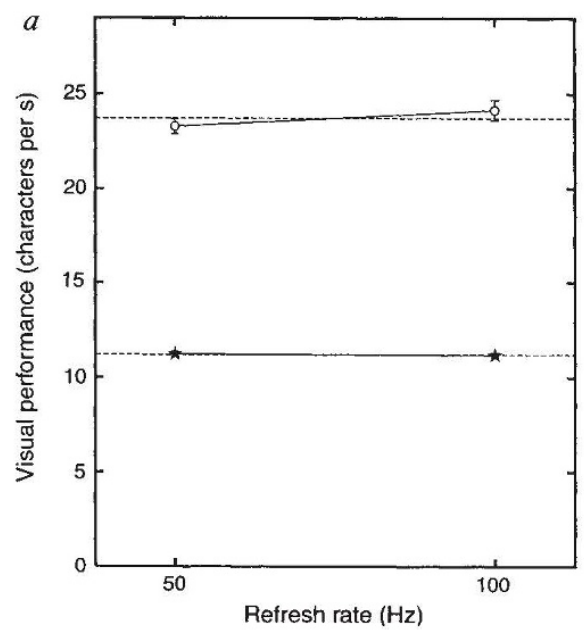

facilitate correction for learning effects during the search experiments. In the other task, reading velocity is registered while subjects read simple Dutch texts containing 9 lines each. Two conditions are considered: applying a $100-\mathrm{Hz}$ digital scan (Philips 28PT910A) and a $50-\mathrm{Hz}$ (Philips 28PV7805) television set. Both sets are calibrated ${ }^{4}$ to a comfortable luminance contrast ratio of 4.0 , applying an

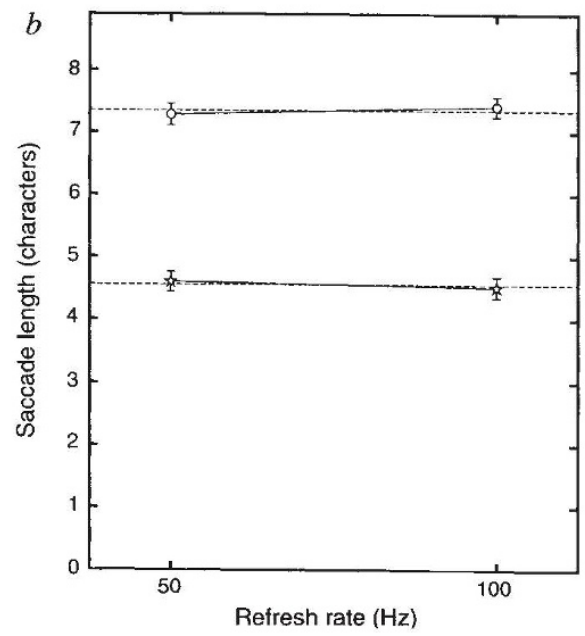

a, Visual performance versus image refresh rate. Reading and search velocity expressed in number of scanned characters per second. Height of error bars (reading) and star symbols (searching) indicates twice the standard error. The large difference between the two measures is explained by the difference in redundancy and work load that exists between the tasks. The search velocity results are the average of 20 subjects performing 18 counts per condition (stars); the reading results are the average of 4 subjects who read 25 texts per condition (open circles). $b$, Length of progressive saccades expressed in number of spanned characters versus image refresh rate. The difference between the results of the tasks is as explained above. The results are the average of 4 subjects counting 12 pseudo-texts (stars) and reading 25 texts (open circles) per condition.

forced-choice task. It is known that each word has an optimal fixation position ${ }^{2}$ from which only small deviations have a disproportionate effect on the recognition process $^{3}$. Therefore, the conclusion of an adverse effect on reading performance would be justified if saccade length is really affected during the reading of a display with a higher refresh rate. Our aim was to investigate whether the length of progressive saccades and visual performance are influenced by image refresh rate.

We used two types of tasks in three experiments involving letter-search and normal reading. Search velocity registered in a letter-search task is known to be a sensitive performance measure that discriminates well between display conditions with respect to legibility factors ${ }^{4,5}$. In this task, subjects scan pseudo-texts and search for target character 'A'. They are asked to press a button each time the target is spotted as a check on their accuracy. In the present case, pseudo-texts consisted of 9 lines with 30 character positions filled with random strings separated by spaces and containing 10-15 targets in total. A set of printed references is included to extreme character luminance of 100 $\mathrm{cd} \mathrm{\textrm {m } ^ { - 2 }}$ and a background luminance of $25 \mathrm{~cd} \mathrm{~m}^{-2}$. The character size is chosen to be comparable to television subtitles; for the letter ' $\mathrm{X}$ ', this is $13.2 \times 29.5$ (width $\times$ height) min of arc at $240 \mathrm{~cm}$ viewing distance.

In the first experiment, search velocity is registered on 20 subjects performing a letter-search task for both conditions. This is repeated on four subjects in the second experiment simultaneously with eyemovement recording. Subjects' eye movements and reading velocity are registered during the reading task in the last experiment. After each session subjects are asked to point out the most comfortable display condition. The searching and reading velocities characterizing visual performance are shown in part $a$ of the figure. Although a positive effect of higher refresh rates is suggested by the reading results, the effects on both measures are found to be statistically insignificant (reading: $F(1,5)=0.58, P=0.48$; searching: $F(1,18)=0.32, P=0.58)$. In part $b$ of the figure, the average extent of progressive saccades is plotted against refresh rate. In neither case is the effect of refresh rate on saccade length statistically significant (reading: $F(1,5)=0.29, P=$ 0.61 ; searching: $F(1,3)=0.58, P=0.50$ ). In all cases subjects indicated the $100-\mathrm{Hz}$ set to be the most comfortable display because of its 'flicker-free' image.

We conclude that visual disturbances that hamper the reading process, if present, are not different for the two refresh rates used. Further, regarding the subjective quality preferences, it is clear that the $100-\mathrm{Hz}$ display is superior to the $50-\mathrm{Hz}$ display.

\section{Martin C. Boschman}

Jacques A. J. Roufs

Institute for Perception Research (IPO),

Eindhoven University of Technology,

PO Box 513, 5600 MB Eindhoven,

The Netherlands

1. Kennedy, A. \& Murray, W. S. Nature 365, 213 (1993).

2. O'Regan, J. K. \& Levy-Schoen, A. in Attention and Performance XII: The Psychology of Reading (ed. Coltheart, M.) 363-383 (Erlbaum, Hillsdale, 1987).

. McConkie, G. W. et al. Percep. Psychophys. 46. 245-253 (1989).

4. Roufs, J. A. J. \& Boschman, M. C. in Vision and Visual Dysfunction Vol.15 The Man-Machine Interface (ed. Roufs, J. A. J.) 24-40 (Macmillan, London, 1991).

5. Boschman, M. C. \& Roufs, J. A. J. in Work With Display Units '92 (eds Luczak, H. et al.) 278-282 (North-Holland, Amsterdam, 1993).

\section{Second subunit of Epo receptor?}

SIR - Ligand-induced homo- or heterooligomerization of cytokine receptors triggers intracellular signal transduction pathways ${ }^{1}$. Homodimerization of the erythropoietin (Epo) receptor cytoplasmic domain has been shown to be sufficient for growth and differentiation signals ${ }^{2,3}$. However, Chiba et al. ${ }^{4,5}$ have published provocative data from which they concluded otherwise. In particular, their studies used chimaeric receptors containing the extracellular domain of the Epo receptor and the cytoplasmic domain of the interleukin (IL-2) receptor $\beta$-chain (E2) or the IL-3 receptor $\beta$-chain (E3). Because these receptors induced an Epo pattern of tryosine phosphorylation ${ }^{4}$ and erythroid differentiation ${ }^{5}$, Chiba et al. concluded that the Epo receptor extracellular domain interacted with other membrane components for signal transduction.

In my view, Chiba et al. did not address the phosphorylation of the chimaeric receptors or the possible expression of the endogenous Epo receptor in the cells. To explore these points, $\mathrm{I}$ used $\mathrm{Ba} / \mathrm{F} 3$ cells expressing wild-type Epo receptor (BF-ER), the E2 chimaeric receptor (BF-E2) or a chimaeric receptor (kit/ER) with the extracellular domain of the oncogene c-kit and the cytoplasmic domain of the Epo receptor $(\mathrm{BF}-\mathrm{K} / \mathrm{E})$. 